\title{
Structure and function of the therapy department of the Open Psychotherapeutic Center
} Dimitris Moschonas

Address: Open Psychotherapy Centre, Athens, Greece

from International Society on Brain and Behaviour: 3rd International Congress on Brain and Behaviour

Thessaloniki, Greece. 28 November - 2 December 2007

Published: 17 April 2008

Annals of General Psychiatry 2008, 7(Suppl I):S4 doi:I0.II86/I744-859X-7-SI-S4

This abstract is available from: http://www.annals-general-psychiatry.com/content/7/SI/S4

(c) 2008 Moschonas; licensee BioMed Central Ltd.

The Therapy Department of the O.P.C. includes a wide range of diagnostic, therapeutic and supportive activities and services for adults, families, children and adolescents. It consists of the Adults' Therapy Unit, the Child and Family Therapy Unit and three Psychotherapeutic Communities. It is addressed to patients who belong to a wide range of diagnostic categories, however the higer percentage of those who addressed are severely disturbed (psychoses, personality disorders, affective disorders).

The application of the multifactorial approach which depending on each case, consists a combination of Dyadic Therapy, Group Analysis, Therapeutic Community, Family Therapy, Pharmacotherapy, appears to be quite effective during the 27 years of our clinical experience. 